\section{Refund fertility-treatment costs for donated embryos}

SIR - Your recent Editorial, Special Report and Commentary article (Nature 442, 601, 606-608 and 629-630; 2006) focused on the ethics of payments to donors of human eggs for research purposes. There is, however, a source of embryos that would not have been generated specifically for this purpose.

The increasing popularity of clinically assisted reproduction has led to an accumulated surplus of frozen embryos in fertility clinics worldwide. Couples who have attained success in clinically assisted reproduction are often faced with the dilemma of what to do with their surplus frozen embryos: whether to discard them, donate them for research or give them to other infertile couples. When such embryos are donated for research, a pertinent question is whether the donor should receive payment, at least to the extent of reimbursement of storage and medical fees.

Clinically assisted reproduction is an expensive medical procedure that imposes a heavy economic burden on sub-fertile couples in countries where the patient pays. Patients undergoing fertility treatment often use their entire savings for the purpose, leaving scant resources for childcare and education. Hence, it seems fair and ethically justifiable for them to receive reimbursement for part of the medical and storage fees that they had previously paid for their treatment, if they later decided to donate their surplus frozen embryos for stem-cell research.

The portion of medical fees most eligible for reimbursement would be the amount of money directly spent on cryopreservation and storage of surplus embryos in liquid nitrogen. Another eligible component is the pro rata cost of superovulatory drugs, which makes up a substantial portion of the medical fees, particularly in the case of highly purified recombinant gonadotropins. For example, suppose that ten embryos are produced during a prospective donor couple's fertility treatment and six of these are used for treatment. If the remaining four embryos are cryopreserved, stored under liquid nitrogen and subsequently donated for stem-cell research, then the fraction of drug prescription costs reimbursed to the patient would be $40 \%$. The reimbursement could come either from the research grant per se, or from another charity or trust supporting stem-cell research. In this manner, former patients who had previously paid hefty medical bills for fertility treatment would receive an influx of much-needed cash for raising their new family.

The chief ethical objection would be the perception of reimbursement being equivalent to the sale and purchase of the human embryo as a marketable commodity.
Nevertheless, it can easily be counter-argued that the payment does not involve embryos donated specifically for research, as patients would be reimbursed only for money that they had already spent in generating surplus frozen embryos in case of initial failure in attempting clinically assisted reproduction. Because patients have to qualify for assistedreproduction programmes, the issue of 'undue incentive' for egg donation does not arise. Of course, it is essential that patients should receive professional counselling so that they can make a well-informed decision, before any reimbursement is given.

Boon Chin Heng, Tong Cao

Stem Cell Laboratory, National University of Singapore, 5 Lower Kent Ridge Road,

119074 Singapore

\section{Dogma, not faith, is the barrier to scientific enquiry}

SIR - Your News story "Genomics luminary weighs in on US faith debate" (Nature 442, 114-115; 2006) reports that the Christian molecular biologist Francis Collins embraces 'theistic evolution' to reconcile scientific facts and religious views.

In his book The Language of God (Free Press, 2006), Collins discusses the ideas of Theodosius Dobzhansky, a darwinist and the main architect of the modern synthetic theory of biological evolution. In a famous article, "Nothing in biology makes sense except in the light of evolution" (Am. Biol. Teach. 35, 125-129; 1973), Dobzhansky described his religious beliefs: "It is wrong to hold creation and evolution as mutually exclusive alternatives. I am a creationist and an evolutionist. Evolution is God's, or Nature's, method of Creation."

In contrast to modern creationists, Dobzhansky accepted macroevolution and the documented age of Earth. He argued that "the Creator has created the living world not by caprice (supernatural fiat) but by evolution propelled by natural selection".

He collaborated for many years with Ernst Mayr, who, when asked about his religious views, replied: "I am an atheist. There is nothing that supports the idea of a personal God. On the other hand, famous evolutionists such as Dobzhansky were firm believers in a personal God. He would work as a scientist all week and then on Sunday get down on his knees and pray to God" (Skeptic 8, 76-82; 2000).

In about 1950, Dobzhansky and Mayr founded our modern 'atheistic' evolutionary theory. Their work showed that Christians and atheists can cooperate to develop scientific theories, as long as religious dogma is not mixed up with facts and experimental data. Unfortunately, this is exactly what young-Earth creationists and intelligent- design theorists are doing. They should read the 1973 essay in which Dobzhansky - an open-minded, non-dogmatic theist — thoroughly refuted their irrational claims. U. Kutschera

Institute of Biology, University of Kassel, HeinrichPlett-Strasse 40, D-34109 Kassel, Germany

\section{Author lists: specify who did what to aid assessment}

SIR - Deciding whether particular contributors deserve to have their names published in a scientific paper and in what order contributors' names should appear is not a simple issue, as highlighted in Correspondence by William F. Laurance ("Second thoughts on who goes where in author lists" Nature 442, 26; 2006).

Nature's formatting guide advises authors to include a "statement to specify the contributions of each co-author" (www. nature.com/nature/authors/gta). If authors of all papers in all journals followed Nature's advice, their contribution would be clear to any reader, irrespective of order of names in the authorship lists.

This information could then be used as a guideline for assessing ranks of scientific productivity by mechanisms such as the UK Research Assessment Exercise. Such organizations would need rules for giving credit for each kind of contribution, which would not be an easy task. Nevertheless, in that the authors themselves have agreed their individual contributions to a published paper, this process should be easier than trying to institute a global rule for authorship order that can fairly be applied to many different disciplines.

I am the only contributor for the development and organization of the ideas within this Correspondence.

Marcos V. C. Vital

Universidade Federal de Viçosa,

Departamento de Biologia Geral,

36570-000 Viçosa, Minas Gerais, Brazil

\section{And finally...}

SIR - We read with interest William F. Laurance's Correspondence letter "Second thoughts on who goes where in author lists" (Nature 442, 26; 2006). We have also noted in this and other journals an increasing number of papers with joint first authors. Perhaps the time has come to accept joint last authors?

R. Martyn Bracewell, Steve Tipper ${ }^{\star}$, Robert Rafal*

Wolfson Centre for Clinical and Cognitive

Neuroscience, University of Wales,

Bangor LL57 2AS, UK

*These authors contributed equally minimal amounts to this letter 